\title{
Organically modified hydrotalcite for compounding and spinning of polyethylene nanocomposites
}

\author{
I. Dabrowska ${ }^{1}$, L. Fambri ${ }^{1 *}$, A. Pegoretti ${ }^{1}$, G. Ferrara ${ }^{2}$ \\ ${ }^{1}$ Department of Industrial Engineering, University of Trento, via Mesiano 77, 38123 Trento, Italy, National Interuniversity \\ Consortium for Science and Technology of Materials (INSTM), Via G. Giusti 9, 50121 Firenze, Italy \\ ${ }^{2}$ LyondellBasell Industries - Basell Poliolefine Italia S.r.l. 'Giulio Natta' R\&D, P.le Donegani 12, 44100 Ferrara, Italy
}

Received 4 June 2013; accepted in revised form 27 July 2013

\begin{abstract}
Organically modified hydrotalcite is a recent class of organoclay based on layered double hydroxides (LDH), which is anionically modified with environmental friendly ligands such as fatty acids. In this paper the influence of hydrotalcite compounded/dispersed by means of two different processes for production of plates and fibers of polyolefin nanocomposites will be compared. A polyethylene matrix, suitable for fiber production, was firstly compounded with various amounts of hydrotalcite in the range of $0.5-5 \%$ by weight, and then compression moulded in plates whose thermomechanical properties were evaluated. Similar compositions were processed by using a co-rotating twin screw extruder in order to directly produce melt-spun fibers. The incorporation of clay into both bulk and fiber nanocomposites enhanced the thermal stability and induced heterogeneous nucleation of polyethylene crystals. Hydrotalcite manifested a satisfactory dispersion into the polymer matrix, and hence positively affected the mechanical properties in term of an increase of both Young's modulus and tensile strength. Tenacity of nanocomposite as spun fibers was increased up to $30 \%$ with respect to the neat polymer. Moreover, the addition of LDH filler induced an increase of the tensile modulus of drawn fibers from 5.0 GPa (neat HDPE) up to 5.6-5.8 GPa.
\end{abstract}

Keywords: nanocomposites, hydrotalcite, polyethylene (HDPE), fiber spinning, mechanical properties

\section{Introduction}

In recent years several research efforts have been focused on the preparation of polymer/layered inorganic nanocomposites [1-3] because of the excellent properties in comparison to the neat polymer. The main reason of this interest lies certainly in the properties of the nanoclay, like high stiffness, and high aspect ratio, that may induce enhancement of various polymer properties (thermal stability, mechanical properties, flame resistance and gas barrier) even with small amount of filler [3,4]. The nanocomposite materials can exhibit properties over those expected from continuum mechanics predictions, not achieved with larger scale rein- forcement [5]. Moreover, nanocomposites can be processed more easily than microcomposites.

Most of the research has been focused on the smectite-type fillers, such as montmorillonite or hectorite. On the contrary, much less work [6-11] has been focused on the effects of layered double hydroxides $(\mathrm{LDH})$ in polyolefins. The structure of $\mathrm{LDH}$, also referred as hydrotalcite, is derived from brucite or $\mathrm{Mg}(\mathrm{OH})_{2}$, where some $\mathrm{Mg}^{2+}$ cations are replaced by trivalent cations yielding positively charged layer [6-8]. Organic modification is adopted to enlarge the interlayer distance of the pristine clay and to increase the hydrophobic nature, thus decreasing the interaction between platelets in order to

\footnotetext{
*Corresponding author, e-mail: luca.fambri@unitn.it

(c) BME-PT
} 
facilitate its dispersion in hydrophobic polymers [6]. The commercially available nanoparticles consist of aggregates or stacks of platelets which are broken up by stress applied during melt mixing. With proper processing conditions, organically modified nanofiller can be melt-dispersed into polyolefins and exfoliated, while it is not very good as that observed in polyamides, polyurethanes, and some other polar polymers [5]. However, significant improvement of thermo-mechanical, flame retardant, barrier, rheological properties and frequently better thermoforming properties were observed in nanofilled polyethylene $[6-8,12]$, polypropylene [10] and polybutene [11].

Some polyolefin nanocomposites have been also processed by melt spinning, that is the most common textile process [13]. However, it should be noted that even in the case of low molecular weight polymers, the presence of nanofiller and sometimes the lower level of chain extension determine the formation of various type of defects, and hence relatively low modulus and strength values of the spun fibers. In the case of polyethylene fibers, both linear low density and high density polymers at very low melt flow, between 0.27 and $0.9 \mathrm{dg} / \mathrm{min}\left(190^{\circ} \mathrm{C}\right.$, $2.16 \mathrm{~kg}$ ), were spun with various organo-modified clays or with fumed silica [14-18]. The high molecular weight of polymers allowed an efficient drawing process and the achievement of higher mechanical properties of drawn nanocomposite fiber with respect to those of neat polymer. In particular, the organo-modified clay was considered responsible for the reduction of the fiber defects during drawing and for the higher attainable draw ratios [17]. On the other hand, various authors described the production of isotactic polypropylene fibers containing organo-modified clay with a double-step process consisting in a preliminary melt compounding with or without compatibilizer, followed by fiber spinning [19-22] or melt-spun bonding [23]. The fiber properties were found to be dependent on the polypropylene melt flow, ranging between 12 and $35 \mathrm{dg} / \mathrm{min}$ $\left(230^{\circ} \mathrm{C}, 2.16 \mathrm{~kg}\right)$, the nanoclay composition, and the spinning and drawing conditions. Recently, the preparation of polypropylene-nanoclay composite fibers starting from hydrotalcite has been described by Guo and Hagstrom [24].

The present work details the formulation of hydrotalcite/polyethylene composite and the production of melt spun fiber. In particular, HDPE was com- pounded via melt mixing with an organically modified hydrotalcite masterbatch. Processing and properties of both compression molded plates and melt spun fibers are reported.

\section{Experimental \\ 2.1. Materials}

High density polyethylene Eltex ${ }^{\circledR}$ A4009 (density $0.96 \mathrm{~g} / \mathrm{cm}^{3}$; melt flow index $0.85 \mathrm{dg} / \mathrm{min}$ at $190^{\circ} \mathrm{C}$, $2.16 \mathrm{~kg}$ ) was supplied by BP Solvay (Brussels, Belgium) in the form of fine powder.

Synthetic hydrotalcite organically modified with fatty acid, Perkalite F100 from Akzo-Nobel (CAS number 39366-43-3 and 67701-03-5; density 1.35$1.40 \mathrm{~g} / \mathrm{cm}^{3}$ ) was provided from Clariant Masterbatches S.p.A. (Pogliano Milanese, MI, Italy) in the form of HDPE pellets containing $12 \%$ by weight of LDH and $12 \%$ by weight of maleated polyethylene (HDPE-g-MA) as compatibilizer. Before processing, masterbatch was dried in a vacuum oven for $24 \mathrm{~h}$ at $90^{\circ} \mathrm{C}$.

\subsection{Processing}

Samples of both neat and nanofilled polymers were prepared by using two types of manufacturing processes: i) plates were produced by mixing in an internal mixer and compression molding; ii) fibers were obtained in a single step by extrusion/compounding in a twin screw extruder.

In the case of plate production, HDPE powder and the selected amount of clay $(0.5,1,2$ and $5 \%$ by weight) were physically mixed at room temperature according to the percentage formulation summarized in Table 1. Each mixture was melt compounded in a co-rotating Thermo-Haake (Karslruhe, Germany) Polylab Rheomix internal mixer $\left(155^{\circ} \mathrm{C}\right.$; rotor speed $60 \mathrm{rpm}$; residence time 10 minutes). Subsequently, square sheets $(160 \mathrm{~mm}$ wide and $1.5 \mathrm{~mm}$ thick) were obtained by compression molding in a Carver (Wabash, IN, USA) Laboratory press $\left(155^{\circ} \mathrm{C}\right.$; 10 minutes; consolidation pressure $\left.0.2 \mathrm{MPa}\right)$. The molten plates were then water cooled at $20^{\circ} \mathrm{C} \cdot \mathrm{min}^{-1}$.

Neat HDPE and nanofilled HDPE fibers were produced after direct mixing and compounding of selected formulation by using a Thermo Haake (Karslruhe, Germany) PTW16 intermeshing co-rotating twin screw extruder (screw diameter $=16 \mathrm{~mm}$; $L / D$ ratio $=25$; rod die diameter $1.65 \mathrm{~mm}$ ). The screws rotation speed was regulated in the range of 
Table 1. Designation and formulation of HDPE nanocomposites (in percentage by weight). Dependence of melt flow $\left(230^{\circ} \mathrm{C}, 2.16 \mathrm{~kg}\right)$, hardness Shore D and Vicat Softening Temperature VST on the composition

\begin{tabular}{|l|c|c|c|c|c|c|}
\hline $\begin{array}{c}\text { Sample } \\
\text { designation }\end{array}$ & $\begin{array}{c}\text { HDPE } \\
{[\%]}\end{array}$ & $\begin{array}{c}\text { Compatibilizer HDPE-g-MA } \\
{[\%]}\end{array}$ & $\begin{array}{c}\text { Hydrotalcite } \\
{[\%]}\end{array}$ & $\begin{array}{c}\text { MFI } \\
{[\mathbf{d g} / \mathbf{m i n}]}\end{array}$ & $\begin{array}{c}\text { Shore D } \\
{[\mathbf{H s}]}\end{array}$ & $\begin{array}{c}\text { VST } \\
{\left[{ }^{\circ} \mathbf{C}\right]}\end{array}$ \\
\hline HDPE & 100 & 0 & 0 & $0.90 \pm 0.03$ & $62.2 \pm 0.6$ & $136.6 \pm 0.3$ \\
\hline Masterbatch & 76 & 12 & 12 & $1.59 \pm 0.02$ & $62.0 \pm 0.5$ & $127.8 \pm 1.5$ \\
\hline LDH-0.5 & 99 & 0.5 & 0.5 & $0.91 \pm 0.03$ & $62.5 \pm 0.5$ & $135.9 \pm 0.4$ \\
\hline LDH-1 & 98 & 1 & 1 & $1.03 \pm 0.02$ & $64.5 \pm 0.6$ & $135.8 \pm 0.6$ \\
\hline LDH-2 & 96 & 2 & 2 & $1.12 \pm 0.02$ & $64.3 \pm 0.6$ & $135.4 \pm 0.5$ \\
\hline LDH-3 & 94 & 5 & 3 & - & - & - \\
\hline LDH-5 & 90 & 5 & 5 & $1.26 \pm 0.03$ & $63.5 \pm 0.4$ & $134.0 \pm 0.4$ \\
\hline
\end{tabular}

3-5 rpm with residence time of $20 \mathrm{~min}$ in order to produce HDPE and nanofilled polyethylene fibers with diameter of about $500 \mu \mathrm{m}$. The temperature profile was gradually increased from hopper to rod $\operatorname{die}(\mathrm{T} 1=130, \mathrm{~T} 2=200, \mathrm{~T} 3=210, \mathrm{~T} 4=220, \mathrm{~T} 5=$ $220^{\circ} \mathrm{C}$ ) with an output of $140 \mathrm{~g} / \mathrm{h}$. The spun fibers were rapidly cooled in water and wounded around a collecting roll/drum at room temperature.

Fibers were drawn ten times at $100^{\circ} \mathrm{C}$ by using a modified hot-plate drawing apparatus (SSM-Giudici srl, Galbiate, LC, Italy), defining the draw ratio, DR, as the ratio between the initial $D_{\mathrm{i}}$ and final $D_{\mathrm{f}}$ diameter according to Equation (1):

$D R=\left(\frac{D_{\mathrm{i}}}{D_{\mathrm{f}}}\right)^{2}$

Nanocomposites were designated as LDH (hydrotalcite abbreviation) followed by the filler percentage by weight. For instance, LDH-2 indicates a nanocomposite sample filled with $2 \mathrm{wt} \%$ of hydrotalcite.

\subsection{Characterization}

Melt Flow Index measurements were performed by a Dynisco LMI 400 plastometer (Heilbronn, Germany) according to ASTM D1238-10. About 3 grams of material were preheated at $190^{\circ} \mathrm{C}$ for 5 min following procedure $\mathrm{A}$ and then extruded with an applied load of $2.16 \mathrm{~kg}$.

Scanning electron micrographs (SEM) were obtained by using a Philips XL30 Environmental Scanning Electron Microscopy (Eindhoven, The Netherlands), at an acceleration voltage between 20 and $25 \mathrm{kV}$. Samples were fractured in liquid nitrogen.

The XRD analysis over $2 \theta=1.8-40^{\circ}$ for plates and $2 \theta=3-30^{\circ}$ for fibers, in steps of $0.02^{\circ}$ and $5 \mathrm{~s}$ measuring time for each point were carried out using a Rigaku III D-Max diffractometer (Tokyo, Japan) in the Bragg-Brentano configuration with $\mathrm{Cu}-\mathrm{K}_{\alpha}$ radiation $(\lambda=0.154 \mathrm{~nm})$ generated at $30 \mathrm{~mA}$ and $40 \mathrm{kV}$. Shore D hardness was evaluated according to ASTM D2240-05 at $25^{\circ} \mathrm{C}$ on $3 \mathrm{~mm}$ thick rectangular specimen by using an ATS-Faar S.p.A (Milano, Italy) durometer as average of 5 measurements in different positions under an indentation time of 5 sec.

Vicat softening temperature (VST) was measured by a HDT-VICAT instrument from ATS-Faar S.p.A (Milano, Italy) following ASTM D1525-09. Three specimens of $3 \mathrm{~mm}$ thickness were used in each test (heating rate of $50^{\circ} \mathrm{C} / \mathrm{h}$; applied load of $10 \mathrm{~N}$ ).

Dynamic mechanical thermal analysis (DMTA) was performed on $12 \times 5 \times 1.0 \mathrm{~mm}$ samples with a DMA Q800 testing unit (TA Instruments, New Castle, DE, USA). The experiments were carried out in tensile mode by applying a sinusoidal strain with a frequency of $1 \mathrm{~Hz}$ and amplitude of 64 microns under a preload force of $10 \mathrm{~N}$ (constant stress of $2 \mathrm{MPa})$.

Thermal degradation was studied in the range 50$600^{\circ} \mathrm{C}$ by a thermobalance Mettler TG 50 (Schwarzenbach, Switzerland) on sample of about $15 \mathrm{mg}$ at a heating rate of $10^{\circ} \mathrm{C} / \mathrm{min}$ with an air flow of $100 \mathrm{~mL} / \mathrm{min}$. The results represent the average of three tests.

Density measurements were performed by using a Micromeretrics Accupyc 1330 helium pycnometer (Norcross, GA, USA) at $23.0^{\circ} \mathrm{C}$. A testing chamber of $3.5 \mathrm{~cm}^{3}$ was used, and 30 measurements were replicated for each specimen. Standard deviation on each measurement was $\pm 0.001 \mathrm{~g} / \mathrm{cm}^{3}$.

Differential scanning calorimetry (DSC) analysis was performed on samples of about $15 \mathrm{mg}$ in $160 \mu \mathrm{L}$ aluminum crucible by using a Mettler DSC 30 calorimeter (Schwarzenbach, Switzerland), in the range $0-200^{\circ} \mathrm{C}$ with a heating and cooling cycle at $\pm 10^{\circ} \mathrm{C} / \mathrm{min}$ flushing nitrogen at $100 \mathrm{~mL} / \mathrm{min}$. The 
crystallinity percentage of HDPE $X_{\mathrm{HDPE}}$ was calculated according to Equation (2):

$X_{\mathrm{HDPE}}=100 \cdot \frac{\Delta H_{\mathrm{i}}}{\Delta H_{\mathrm{HDPE}} \cdot(1-f)}$

where $\Delta H_{\mathrm{i}}$ is the melting enthalpy, $\Delta H_{\mathrm{HDPE}}$ is the reference enthalpy of a fully crystalline polyethylene, taken as $293 \mathrm{~J}^{-g^{-1}}$ [25], and $f$ is the weight fraction of nanofiller.

Mechanical properties of plates and fibers were performed at room temperature by using an Instron 4502 (Norwood, MA, USA) dynamometer, equipped with load cells of $1 \mathrm{kN}$ and $100 \mathrm{~N}$, respectively. Rectangular specimens ( $80 \mathrm{~mm}$ long, $5 \mathrm{~mm}$ wide and $1.5 \mathrm{~mm}$ thick) and fiber specimens (diameter 500 and 158 micron; gauge length $30 \mathrm{~mm}$ ) were tested at a cross-head speed of $50 \mathrm{~mm} \cdot \mathrm{min}^{-1}$. According to ISO 527 standard, the elastic modulus was determined as a secant value between deformation levels of 0.05 and $0.25 \%$. The results represent the average of at least three specimens.

\section{Results and discussion}

\subsection{Compounding and morphology}

As reported in Table 1, the investigated formulations are a combination of polyethylene with the nanofiller LDH and the compatibilizer. It should be noted the higher MFI of the masterbatch, and consequently the MFI values increased with the percentage of hydrotalcite in the polymer matrix, with an almost linear dependence on the HDPE-LDH composition (Table 1).

The effect of compounding and the quality of hydrotalcite dispersion into HDPE matrix was evaluated from ESEM analysis of cryo-fractured surfaces of HDPE-LDH nanocomposites. Figure 1a evidences the presence of various agglomerates with dimensions in the range between 5 and 15 microns in the masterbatch containing $12 \mathrm{wt} \%$ of hydrotalcite. These agglomerates need to be properly disaggregated and dispersed in HDPE compounds during processing otherwise these defects and stress concentration points could prevent the drawability in fiber spinning [22]. ESEM analysis evidenced the progressive dispersion of LDH in polyethylene matrix. An almost satisfactory result was obtained in compounding through internal mixer for various compositions, as evidenced from the particle dimension at the fracture surface in comparison with that of the masterbatch (Figure 1a).
For instance LDH particles of $0.25-0.40$ microns and other aggregates of about 0.8 micron were observed in plates at 5\% of LDH (Figure 1b). The dimension of both aggregates and particles was found to reduce with the masterbatch content. Figure 1c shows the fracture surface of LDH-1 plate, for which particles of about $0.20-0.35$ micron and aggregates up to 0.6 micron were evidenced.

In the case of fibers filled with $\mathrm{LDH}$, some lower size particles were revealed, indicating that twinscrew processing allowed a submicron level of dispersion especially at low hydrotalcite content, as in the case of LDH-0.5 fiber, for which particles of $0.15-0.24$ micron were shown in Figure 1d.

The XRD analysis is a very useful method to describe the extent of intercalation and exfoliation of the nanofiller having layered structure. The XRD analysis for HDPE-LDH plates and fibers are reported in Figure $2 a$ and $2 b$ respectively. The XRD pattern was interpreted with respect to the position of the basal peak (003), which depends on the distance between two adjacent metal hydroxide sheets in the LDH crystal lattice. The higher order peaks indicate the presence of repeating crystal planes and symmetry in a specific crystallographic direction [26]. A more intense and sharp peak indicates a more ordered intercalated structure, while less intense and broader peak testify the existence of a disordered intercalated structure [27]. XRD spectrum of LDH-5 plate evidences the two characteristic Bragg reflections of $\mathrm{LDH}$ presence at about $4.9^{\circ}$ (003) and $11.2^{\circ}(006)$, in agreement to the ICPDS Powder Diffraction File (LDH number 41-1428). According to some authors [26] the third peak at $8.4^{\circ}$ is attributed to $\mathrm{LDH}$, while it is not included in the ICPDS standard for Al-Mg LDH; however it might be related to the phase derived from primary clay, like Dypingite, $\mathrm{Mg}_{5}\left(\mathrm{CO}_{3}\right)_{4}(\mathrm{OH})_{2} \cdot 5 \mathrm{H}_{2} \mathrm{O}$. For the compositions LDH-2 and LDH-1 with lower nanofiller content only the main peak at $11.2^{\circ}$ is well detectable, whereas the two others appear weak and broad. Moreover, XRD spectrum of LDH-5 suggests the presence of another and very intensive reflection at about $1.9^{\circ}(001)$, even if not completely visible in Figure 2a, that could be attributed to the presence of bulk LDH nanoplatelets [28].

XRD spectra of HDPE-LDH fibers containing 1 and $2 \%$ of hydrotalcite reported in Figure $2 b$ show the characteristic reflections attributed to LDH particles, the very weak peaks and the shift to lower $2 \theta$ 


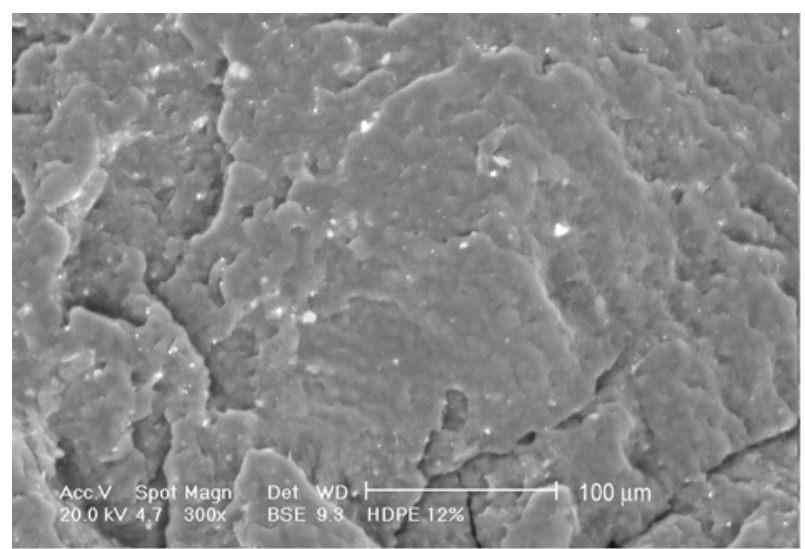

a)

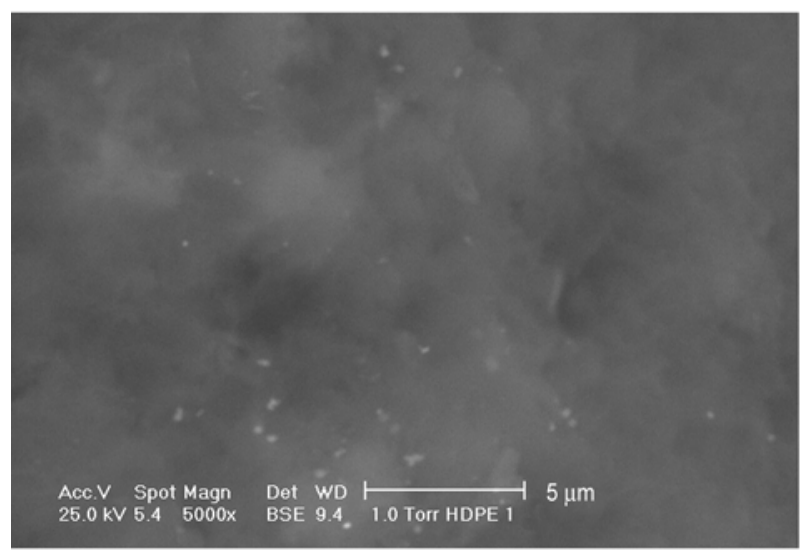

c)

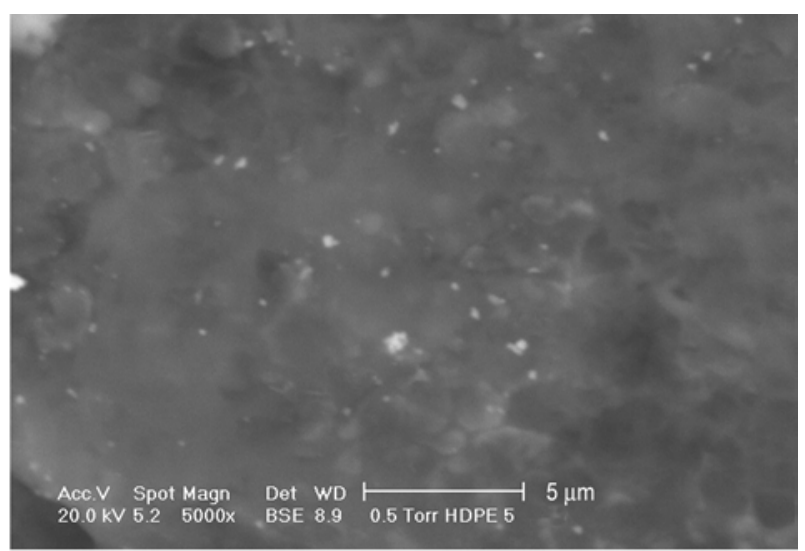

b)

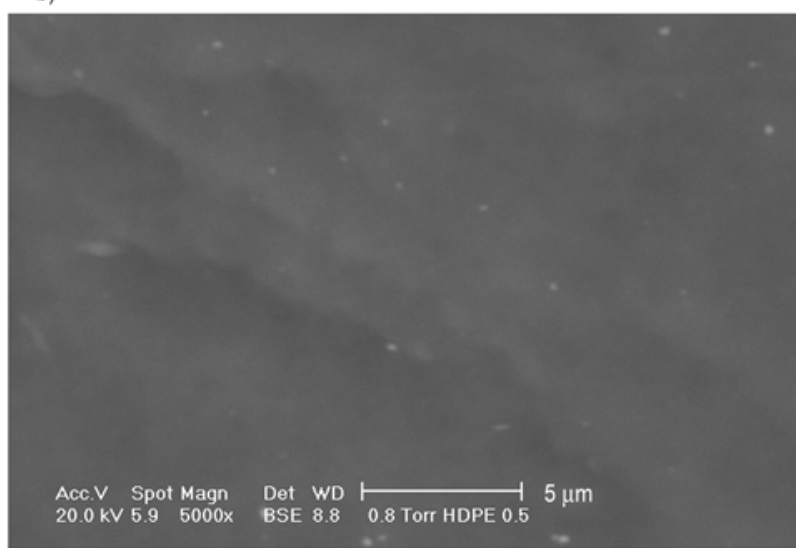

d)

Figure 1. a) ESEM micrograph of masterbatch (fracture surface), b) ESEM micrograph of LDH-5 plate (fracture surface), c) ESEM micrograph of LDH-1 plate (fracture surface), d) ESEM micrograph of LDH-0.5 fiber (fracture surface)

$\left(4.4,8.1\right.$ and $\left.11.0^{\circ}\right)$. It is known that a complete degree of exfoliation of layered crystalline fillers in polymer matrix determines the disappearance of corresponding peaks in the XRD spectra of the composites. However, the absence of the peak could be also related to the very low concentration of the filler [6]. Some of these results might suggest a possible intercalation with partial exfoliation, as reported by other researchers [10, 26-30]. Moreover, after comparison of Figures $2 a$ and $2 b$, the lower intense reflections of fibers with respect to those of plates, at the same ( 1 and $2 \%$ by wt.) nanofiller content, could suggest that the layer of LDH were better intercalated and partially exfoliated in the polymer during melt compounding/spinning in twin-screw extrusion.
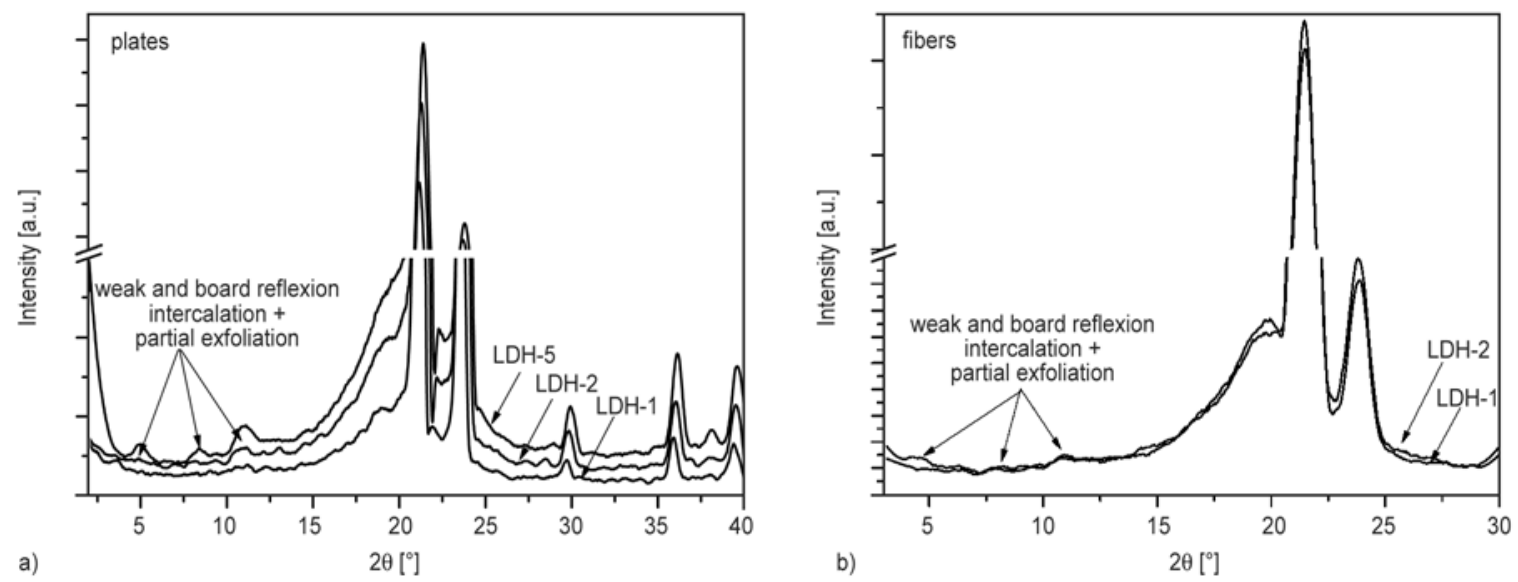

Figure 2. a) XRD patterns of HDPE-LDH nanocomposites plates with different nanofiller content, b) XRD patterns of HDPE-LDH nanocomposites fibers with different nanofiller content 


\subsection{Compression molded plates (Shore D, Vicat and DMTA)}

Shore hardness (Hs) and Vicat softening temperature (VST) are interesting data for the initial comparison of nanocomposite compression molded plates, being related to the tip penetration at room temperature and during heating, respectively. Higher Shore D values of polymer nanocomposites (about 63-64 Hs) with respect to $62.2 \mathrm{Hs}$ for polyethylene evidence the effect of nanofiller, as reported in Table 1. The highest hardness value was obtained for LDH-1 (64.5 Hs), while at higher LDH content the reinforcement action is progressively counterbalanced by the presence of various agglomerates (lower interfacial interaction), reaching for LDH-5 value equal to $63.5 \mathrm{Hs}$.

Vicat Softening Temperature (VST) gives a useful indication of the relative rigidity at high temperature (Table 1). VST value progressively decreased with the percentage of hydrotalcite in the polymer matrix, in particular from $136.6^{\circ} \mathrm{C}$, for neat HDPE, to about $135-136^{\circ} \mathrm{C}$ for $\mathrm{LDH}$ content in the range $0.5-2 \%$, and to $134.0^{\circ} \mathrm{C}$ for LDH-5 respectively.

The results of dynamic mechanical analysis of neat HDPE and nanofilled HDPE plates are reported in Figure 3. Storage modulus increased with percentage of the organically modified $\mathrm{LDH}$, particularly at lower temperatures, i.e. from $-120^{\circ} \mathrm{C}$ to $-20^{\circ} \mathrm{C}$, and the highest values were obtained for LDH-5 and LDH-1, as shown in Figure 3. These results could be tentatively attributed to the combined effects of both the filler content and the polymer microstructure (note that hardness values present a maximum for LDH-1). On the other hand at higher temperature above $0^{\circ} \mathrm{C}$, both neat HDPE and

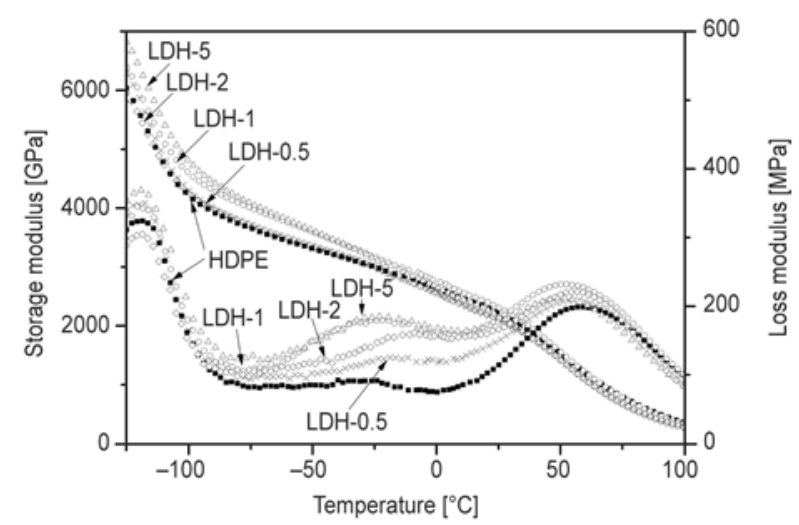

Figure 3. Storage modulus and loss modulus of neat HDPE plates (घ) and nanocomposites HDPE plates containing $0.5 \%(\times), 1 \%(\circ), 2 \%(\diamond)$ and $5 \%(\Delta)$ of $\mathrm{LDH}$, respectively
HDPE-LDH nanocomposites exhibited a similar storage modulus, with some minor differences. In the range $0-50^{\circ} \mathrm{C}$ the highest storage modulus was found for LDH-1. A similar behavior in the case of LDPE/silica composite was explained from Kontou and Niaounakis by considering the coexistence in the matrix of composite two parts, i.e. the bulk free part and the interphase formed by the physical/ chemical interaction of polyethylene molecules and/or crystallization on the filler's surface [31]. Loss modulus evidences in Figure 3 the three main relaxations of polyethylene $\alpha, \beta$ and $\gamma$ at about 50, -40 and $-120^{\circ} \mathrm{C}$ respectively, according to literature $[32,33]$. The $\beta$ relaxation, related to the movement of the chain units in the interfacial region [32, $34]$, typically dependent on branching, is practically absent in the case of neat HDPE, as previously shown for HDPE with melt flow $1.15 \mathrm{dg} / \mathrm{min}$ [35]. After addition of $0.5 \% \mathrm{LDH}$, the $\beta$-peak appears in the zone -50 and $0^{\circ} \mathrm{C}$, and it becomes more intense for higher percentage of hydrotalcite [36], as a combined effect of the higher amount of fatty acid, the organo-modifier agent, and the higher interfacial region due to the higher percentage of nanofiller. The position of loss modulus $\alpha$-peak moved to lower temperature after addition of hydrotalcite masterbatch, i.e. from $59^{\circ} \mathrm{C}$ of the neat HDPE to $52^{\circ} \mathrm{C}$ in the case of LDH-5. Moreover, the intensity of the $\alpha$-peak in loss modulus curves of LDH-composites is higher than that of neat HDPE, in direct dependence on the crystallinity of the polymer matrix.

\subsection{Thermal properties of plates and fibers}

Following the initial characterization of HDPELDH plates up to $5 \%$ of hydrotalcite, various compositions with a maximum $3 \%$ of $\mathrm{LDH}$ were also compounded and extruded for fiber production. In particular, this paragraph will describe and compare thermogravimetry results, density and calorimetric data of both plates and fibers with LDH.

Representative TGA curves of plates are reported in Figure 4, evidencing the beneficial effect of organically modified hydrotalcite on the thermal degradation resistance not only for the masterbatch, but also for all the nanocomposites at $0.5-5 \% \mathrm{LDH}$, with respect to the neat HDPE. Similar results were observed in the case of fibers, where the curves of nanofilled HDPE appeared shifted at higher temperature. 


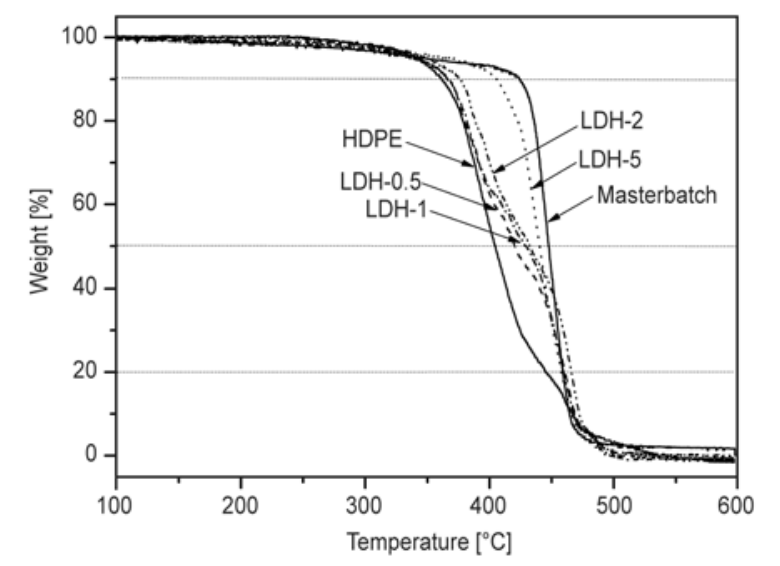

Figure 4. TGA thermograms of neat HDPE and HDPE nanocomposites plates with different LDH content (from 0.5 up to $12 \%$ by wt)

The comparison of thermal stability was carried out in terms of selected decomposition temperatures, in particular the initial degradation at $10 \%\left(T_{0.1}\right)$, and the temperatures $T_{0.5}$ and $T_{0.8}$ at which occurred 50 and $80 \%$ of mass loss, respectively. The decomposition temperatures $\left(T_{0.1}, T_{0.5}, T_{0.8}\right)$ of HDPE-LDH plates and fiber, summarized in Table 2, were found to be higher than those of neat HDPE, even at low hydrotalcite content with a stabilizing effect of nanofiller particles under oxidizing conditions. Following Gilman's suggestion [37], this behavior is due to the hindered thermal motion of the polymer molecular chain. At the same time the selected decomposition temperatures tend to increase with LDH content. However some discrepancies from linearity could be attributed to the parallel contribution of the nanofiller dispersion, particularly at higher mass loss. For instance in the case of fiber and plates containing $1 \%$ of $\mathrm{LDH}$, it is worth noting that $T_{0.8}$ was found at a higher temperature than that of masterbatch at $12 \%$ of LDH content, 460 vs. $458^{\circ} \mathrm{C}$, respectively. The slightly lower degradation temperature of HDPE nanocomposite fibers with respect to plates could be attributed to the higher surface of fiber in oxidizing atmosphere.

Residual mass at $600^{\circ} \mathrm{C}$ is directly dependent on the nanofiller content, ranging between $0.4 \%$ for composition LDH- 0.5 up to about $1.8 \%$ for LDH-3 fiber and LDH-5 plate. HDPE masterbatch (12 $\mathrm{wt} \%$ of LDH content) plate exhibited a relevant mass loss of about $3 \%$ weight in the range $230-280^{\circ} \mathrm{C}$, and a final residue of $4 \%$ at $600^{\circ} \mathrm{C}$.

Hence, these LDH nanocomposites showed in TGA test a charring process with formation of a charred layer, which enhances the material thermal stability, in conformity to literature results $[38,39]$. In fact, the incorporation of clay into a polyolefin matrix enhances its thermal stability by acting as a superior insulator and mass transport barrier to the volatile products generated during decomposition, making the diffusion path of the oxygen more tortuous, and thus retarding the thermo-oxidative process $[2,7$, 40].

Bulk properties of plates and fibers were compared in term of density, as shown in Table 3. The results evidenced a direct dependence not only on the composition, but also on the different processing. The higher the LDH content, the higher the density, in between the density $0.957 \mathrm{~g} / \mathrm{cm}^{3}$ of neat polyethylene and the density of the masterbatch, $0.985 \mathrm{~g} / \mathrm{cm}^{3}$. It should be noted that the density of fiber containing $1-3 \%$ of LDH is higher not only than HDPE fiber, but it is also higher than the correspondent LDH nanocomposite plates. This evidence reveals that density could be influenced from various other factors than LDH content, for instance from the orientation and from the crystallinity.

For such reason, an investigation of plates and fibers was performed through DSC, as shown in Figure 5 where the heating-cooling cycles of HDPE and selected LDH composites were compared. In

Table 2. Selected TGA results of neat HDPE and nanofilled HDPE plates and fibers

\begin{tabular}{|c|c|c|c|c|c|c|c|c|}
\hline \multirow[t]{2}{*}{ Composition } & \multicolumn{2}{|c|}{$\begin{array}{c}\text { Temperature of } 10 \% \\
\text { mass loss }-\mathrm{T}_{0.1} \\
{\left[{ }^{\circ} \mathrm{C}\right]} \\
\end{array}$} & \multicolumn{2}{|c|}{$\begin{array}{c}\text { Temperature of } 50 \% \\
\text { mass loss }-\mathbf{T}_{0.5} \\
{\left[{ }^{\circ} \mathrm{C}\right]} \\
\end{array}$} & \multicolumn{2}{|c|}{$\begin{array}{c}\text { Temperature of } 80 \% \\
\text { mass loss }-\mathrm{T}_{0.8} \\
{\left[{ }^{\circ} \mathrm{C}\right]} \\
\end{array}$} & \multicolumn{2}{|c|}{$\begin{array}{c}\text { Residual mass at } \\
6_{000^{\circ} \mathrm{C}} \\
{[\%]}\end{array}$} \\
\hline & plates & fibers & plates & fibers & plates & fibers & plates & fibers \\
\hline HDPE & $356 \pm 2$ & $358 \pm 2$ & $403 \pm 1$ & $412 \pm 3$ & $444 \pm 6$ & $444 \pm 10$ & $0.0 \pm 0.2$ & $0.0 \pm 0.4$ \\
\hline Masterbatch & 424 & - & 447 & - & 458 & - & 4.0 & - \\
\hline LDH-0.5 & $364 \pm 5$ & $362 \pm 1$ & $420 \pm 5$ & $428 \pm 5$ & $460 \pm 4$ & $454 \pm 3$ & $0.4 \pm 0.4$ & $0.4 \pm 0.1$ \\
\hline LDH-1 & $365 \pm 8$ & $368 \pm 1$ & $428 \pm 2$ & $422 \pm 8$ & $460 \pm 2$ & $460 \pm 6$ & $1.3 \pm 0.1$ & $1.0 \pm 0.3$ \\
\hline LDH-2 & $371 \pm 4$ & $375 \pm 5$ & $433 \pm 3$ & $425 \pm 3$ & $465 \pm 6$ & $454 \pm 4$ & $1.4 \pm 0.3$ & $1.5 \pm 0.1$ \\
\hline LDH-3 & - & $389 \pm 6$ & - & $433 \pm 3$ & - & $452 \pm 4$ & - & $1.8 \pm 1.0$ \\
\hline LDH-5 & $405 \pm 4$ & - & $441 \pm 1$ & - & $455 \pm 1$ & - & $1.8 \pm 0.2$ & - \\
\hline
\end{tabular}


Table 3. Density, melting temperature $\left(T_{\mathrm{m}}\right)$, crystallinity content, and crystallization temperature $\left(T_{\mathrm{c}}\right)$ for pure HDPE and nanofilled HDPE plates and fibers

\begin{tabular}{|l|c|c|c|c|c|c|c|c|}
\hline \multirow{2}{*}{ Composition } & \multicolumn{2}{|c|}{$\begin{array}{c}\text { Density } \\
{\left[\mathbf{g} / \mathbf{c m}^{\mathbf{3}}\right]}\end{array}$} & \multicolumn{2}{c|}{$\begin{array}{c}\text { Melting temperature } \\
{\left[{ }^{\circ} \mathbf{C}\right]}\end{array}$} & \multicolumn{2}{c|}{$\begin{array}{c}\text { Crystallinity } \\
{[\%]}\end{array}$} & \multicolumn{2}{c|}{ Crystallization temperature } \\
& [lates & fibers & plates & fibers & plates & fibers & plates & fibers \\
\cline { 2 - 9 } & 0.957 & 0.954 & 134.6 & 133.4 & 70.8 & 50.5 & 110.0 & 110.8 \\
\hline HDPE & 0.985 & - & 136.9 & - & 62.5 & - & 109.4 & - \\
\hline Masterbatch & 0.958 & 0.945 & 136.7 & 133.0 & 70.0 & 51.7 & 113.5 & 111.8 \\
\hline LDH-0.5 & 0.963 & 0.960 & 137.4 & 133.4 & 71.8 & 53.0 & 114.0 & 112.5 \\
\hline LDH-1 & 0.964 & 0.976 & 137.5 & 132.0 & 71.0 & 54.5 & 115.3 & 112.8 \\
\hline LDH-2 & - & 0.982 & - & 133.0 & - & 53.3 & - & 115.0 \\
\hline LDH-3 & 0.971 & - & 135.0 & - & 70.4 & - & 115.3 & - \\
\hline LDH-5 & & & & & & & & - \\
\hline
\end{tabular}
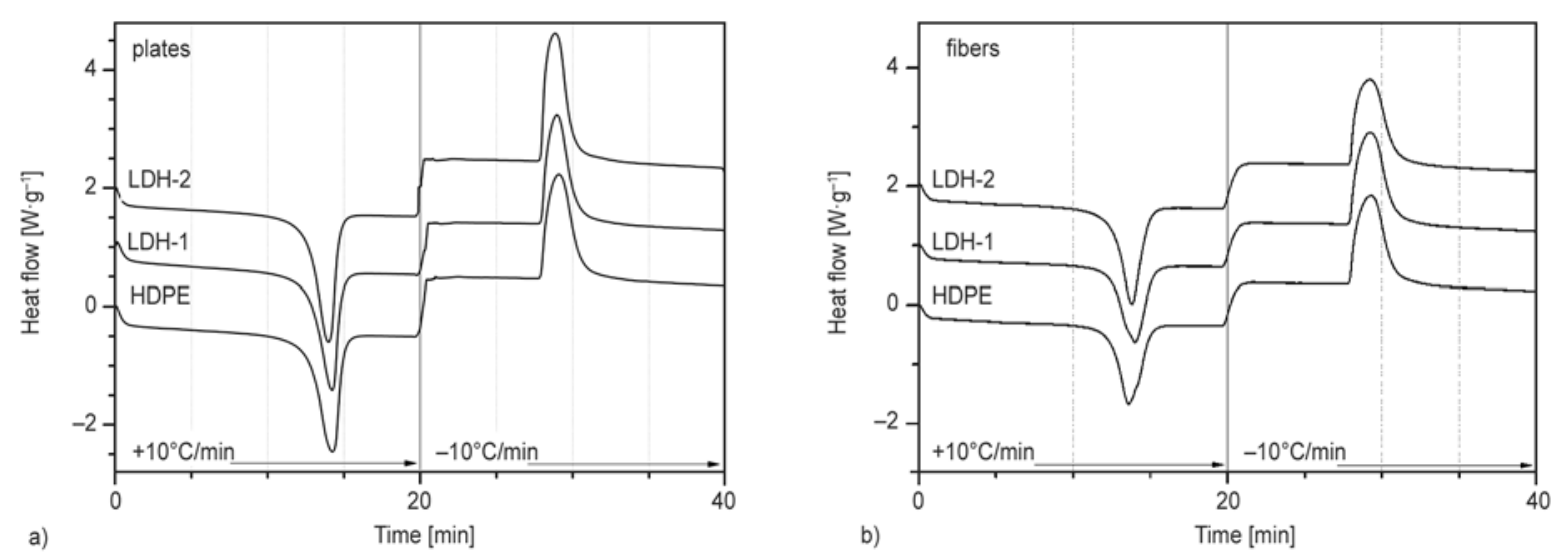

Figure 5. DSC thermograms (heating at $+10^{\circ} \mathrm{C} / \mathrm{min}$ and cooling at $-10^{\circ} \mathrm{C} / \mathrm{min}$ ) of neat $\mathrm{HDPE}$ and nanocomposites plates (a) and fibers (b) with different nanofiller content

Table 3, the relative crystallinity values of polyethylene matrix and the temperatures of melting and crystallization during the heating and the cooling were presented. The melting temperature and particularly the level of crystallinity of fiber samples were lower than the correspondent of plate samples, in this latter case about 50 vs $70 \%$, confirming a peculiar dependence on the thermal history in the processing [41]. Fast cooling in fiber spinning (about $-20^{\circ} \mathrm{C} / \mathrm{sec}$ ) caused not only a quenched crystallization process with the formation of less perfect crystal (and almost constant melting temperature of about $133^{\circ} \mathrm{C}$ ), but also a lower crystallizability. On the other hand, the slow cooling applied for plates (about $-20^{\circ} \mathrm{C} / \mathrm{min}$ ) determined a slow crystallization rate and hence the formation of more perfect crystals at higher melting temperature, from about $135^{\circ} \mathrm{C}$ (HDPE) up to $137^{\circ} \mathrm{C}$ (LDH nanocomposite).

Literature data reported various effects of nanofiller on crystallization temperature and crystallinity content of polyethylene matrix, showing negligible [42], or significant [36, 43] or small differences [12], in dependence on both processing and composition. In our case, the crystallinity of nanofilled polymer was found almost the same in the case of compression molded plates, whereas the final crystallinity of fiber slightly increased with LDH content, in direct conformity to the density measurements.

From the DSC cooling stage, it is noticeable that crystallization temperature of nanocomposites plates and fibers is higher than neat HDPE, i.e. up to 115 versus $110^{\circ} \mathrm{C}$, suggesting a mild effect of $\mathrm{LDH}$ as nucleating agent. Moreover it should also be considered that the higher crystallization temperature of plates with respect to fibers could be attributed to the higher initial crystallinity of plates, particularly associated to the heterogeneous nucleation attributed to hydrotalcite $[10,37]$.

\subsection{Mechanical properties of plates and fibers}

An enhancement of elastic modulus and tensile strength, and a reduction of tensile ductility compared to neat matrix could be expected after a good dispersion of nanofiller [11, 44, 45]. Therefore, mechanical tests were performed on both plates and fibers of various LDH content.

Representative stress-strain curves for plates and fibers are presented in Figures 6, whereas all the 

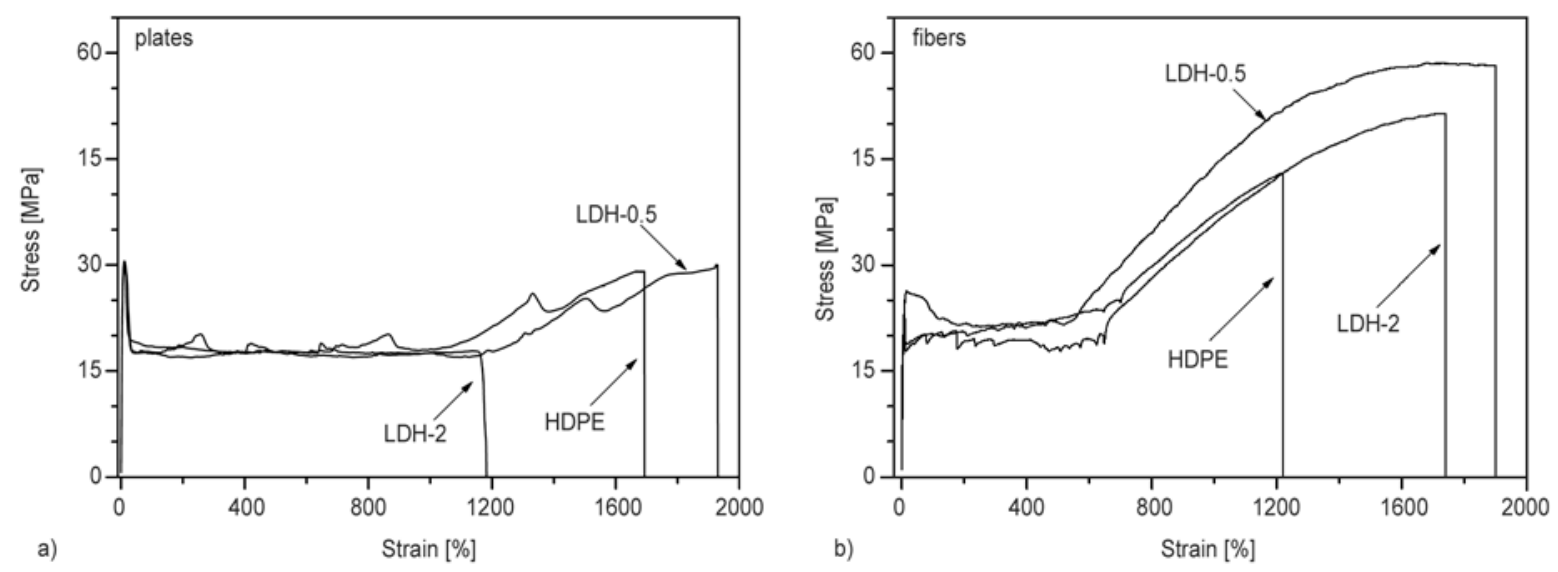

Figure 6. Stress-strain curves of compression molded plates (a) and as-spun fibers (b) of neat HDPE and selected HDPE nanocomposites containing 0.5 and $2 \%$ of $\mathrm{LDH}$

Table 4. Tensile mechanical properties of neat HDPE and nanofilled HDPE plates

\begin{tabular}{|l|c|c|c|c|c|}
\hline \multicolumn{1}{|c|}{ Composition } & $\begin{array}{c}\text { Tensile modulus } \\
{[\mathbf{G P a}]}\end{array}$ & $\begin{array}{c}\text { Yield stress } \\
{[\mathbf{M P a}]}\end{array}$ & $\begin{array}{c}\text { Strain at yield } \\
{[\%]}\end{array}$ & $\begin{array}{c}\text { Stress at break } \\
{[\mathbf{M P a}]}\end{array}$ & $\begin{array}{c}\text { Strain at break } \\
{[\%]}\end{array}$ \\
\hline HDPE & $0.96 \pm 0.01$ & $31 \pm 1$ & $11 \pm 1$ & $26 \pm 4$ & $1766 \pm 166$ \\
\hline LDH-0.5 & $0.95 \pm 0.02$ & $31 \pm 1$ & $11 \pm 1$ & $29 \pm 1$ & $1933 \pm 30$ \\
\hline LDH-1 & $1.01 \pm 0.03$ & $31 \pm 1$ & $11 \pm 1$ & $25 \pm 1$ & $1590 \pm 63$ \\
\hline LDH-2 & $1.03 \pm 0.02$ & $31 \pm 1$ & $11 \pm 1$ & $21 \pm 3$ & $1205 \pm 144$ \\
\hline LDH-5 & $1.04 \pm 0.04$ & $30 \pm 1$ & $14 \pm 1$ & $17 \pm 1$ & $378 \pm 60$ \\
\hline
\end{tabular}

Table 5. Tensile mechanical properties of neat HDPE and nanofilled HDPE fibers (diameter 500 micron)

\begin{tabular}{|l|c|c|c|c|c|c|c|c|c|}
\hline Composition & $\begin{array}{c}\text { Tensile } \\
\text { modulus } \\
{[\mathbf{G P a}]}\end{array}$ & $\begin{array}{c}\text { Yield stress } \\
{[\mathbf{M P a}]}\end{array}$ & $\begin{array}{c}\text { Strain at } \\
\text { yield } \\
{[\%]}\end{array}$ & $\begin{array}{c}\text { Stress at } \\
\text { break } \\
{[\mathbf{M P a}]}\end{array}$ & $\begin{array}{c}\text { Strain at } \\
\text { break } \\
{[\%]}\end{array}$ & $\begin{array}{c}\text { Mechanical } \\
\text { draw ratio }\end{array}$ & $\begin{array}{c}\text { Calculated } \\
\text { maximum } \\
\text { strength } \\
{[\mathbf{M P a}]}\end{array}$ & $\begin{array}{c}\text { Linear } \\
\text { density } \\
{[\text { [tex] }}\end{array}$ & $\begin{array}{c}\text { Tenacity }^{*} \\
{[\mathbf{c N} / \text { tex] }}\end{array}$ \\
\hline HDPE & $0.55 \pm 0.02$ & $22 \pm 2$ & $8 \pm 2$ & $42 \pm 1$ & $1206 \pm 20$ & 13.1 & 549 & 187 & $4.4 \pm 0.1$ \\
\hline LDH-0.5 & $0.53 \pm 0.01$ & $25 \pm 1$ & $16 \pm 1$ & $56 \pm 4$ & $1860 \pm 60$ & 19.6 & 1098 & 185 & $5.9 \pm 0.4$ \\
\hline LDH-1 & $0.60 \pm 0.08$ & $22 \pm 1$ & $11 \pm 4$ & $52 \pm 6$ & $1360 \pm 60$ & 14.6 & 759 & 188 & $5.4 \pm 0.6$ \\
\hline LDH-2 & $0.62 \pm 0.02$ & $22 \pm 1$ & $11 \pm 1$ & $53 \pm 1$ & $1770 \pm 42$ & 18.7 & 991 & 192 & $5.4 \pm 0.1$ \\
\hline LDH-3 & $0.66 \pm 0.02$ & $23 \pm 1$ & $12 \pm 1$ & $43 \pm 1$ & $1470 \pm 70$ & 15.7 & 675 & 193 & $4.4 \pm 0.1$ \\
\hline
\end{tabular}

*for definition of Linear density and Tenacity see ASTM [48].

results are summarized in Table 4 and in Table 5, respectively. As first evidence, the formulation at $0.5 \%$ of organically modified LDH showed the highest ultimate properties of both stress at break and strain at break (about 1900\%), either in the case of plates (Figure 6a) or in the case of fibers (Figure 6b). However at the same time, a slightly lower tensile modulus with respect to HDPE was obtained, $0.95 \mathrm{vs} 0.96 \mathrm{GPa}$ after compression molding (plates), and 0.53 vs $0.55 \mathrm{GPa}$ after spinning (fibers).

At higher LDH content, a progressive stiffening of both plates and fibers was achieved as expected. The elastic modulus increased up to $1.04 \mathrm{GPa}$ for LDH-5 plates, and up to $0.66 \mathrm{GPa}$ for LDH-3 fibers. It is well known that mechanical properties of a nanocomposite depend upon these two factors, crystallinity of the matrix and reinforcement of the filler [38]. For such considerations, if the elastic modulus of polyethylene and LDH-composite will be compared as a function of the crystallinity a good correlation between the two groups of plates and fibers data can be observed. The main difference of modulus values can be directly attributed to the different processing conditions, because they affected the crystallinity content.

A similar dependence on the crystalline content, was also found in the case of yield stress, resulting about $30 \mathrm{MPa}$ for all the plates (with $70-73 \%$ of crystallinity) and about $22 \mathrm{MPa}$ for the fibers (with $50-55 \%$ of crystallinity).

Moreover the effect of the nanofiller content on the tensile modulus can be specifically clarified after 
the comparison of the relative stiffness of plates and fibers. In particular the relative elastic modulus (REM) was calculated as the ratio between the composite modulus $\left(E_{\mathrm{HDPE}-\mathrm{LDH}}\right)$ and the matrix modulus ( $\left.E_{\mathrm{HDPE}}\right)$ according to Equation (3):

$R E M=\frac{E_{\mathrm{HDPE}-\mathrm{LDH}}}{E_{\mathrm{HDPE}}}$

and it was depicted in Figure 7. It is quite evident that the initial reduction for composition at $0.5 \%$ of $\mathrm{LDH}$, is followed by a slight increase in the case of plate up to about $7 \%$ for $\mathrm{LDH}-5$, and a much higher increment for the fibers (about 20\% for LDH-3). This latter effect of stiffening is particularly related to the spinning process, for which the twin screw extrusion at higher temperature determined a better distribution of the filler and the following interaction with the oriented polymer chains.

The comparison of ultimate properties evidenced the higher strength of fibers (Table 5) with respect to plates (Table 4), as result of polymer orientation during the spinning process. Moreover, in the case of fiber a good improvement of stress at break was obtained with hydrotalcite, from 42-46 MPa for neat HDPE, up to 52-56 MPa for nanocomposite at LDH content in the range $0.5-2 \%$. These results could be related to the better filler dispersion and the smaller dimension of hydrotalcite aggregates.

On the other hand, as expected, at higher LDH content, the stiffening effect was also counterbalanced by a consistent and progressive reduction of tensile properties at break, in conformity to other literature data $[12,45,46]$. For instance the strain at break of plates decreased from about $1700 \%$ for HDPE plates to $380 \%$ for LDH-5. The decrease in both

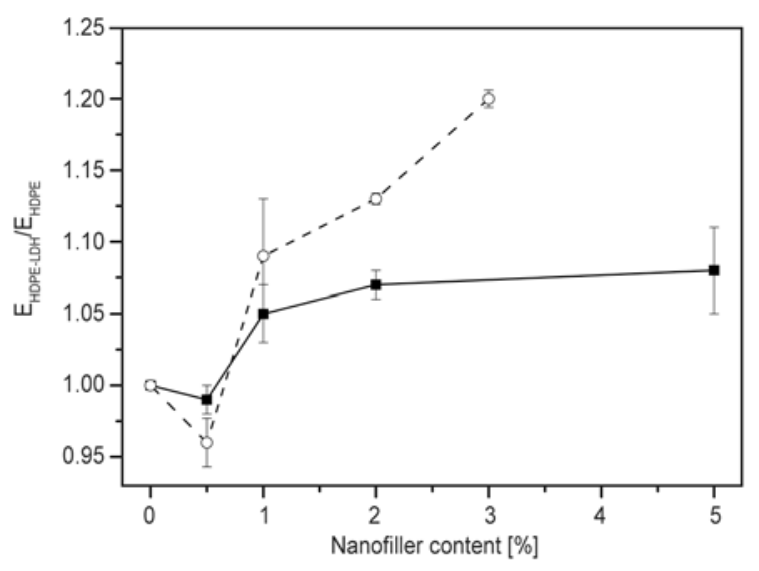

Figure 7. Comparison of relative elastic modulus of plates $(\boldsymbol{\square})$ and fibers ( $($ ) as function of nanofiller content tensile strength and strain at break at high nanofiller content, particularly in LDH-5 plates and LDH-3 fiber, has been attributed to the presence of hydrotalcite aggregates, that may behave as defects, and could also reduce the interfacial adhesion between the matrix and the filler [5, 47].

Some other indications on the fiber drawing can be evaluated from the mechanical draw ratio $\lambda_{\mathrm{MEC}}$, or the maximum drawability that is defined according to Equation (4):

$\lambda_{\mathrm{MEC}}=1+\frac{\varepsilon_{\mathrm{b}}}{100}$

where $\varepsilon_{\mathrm{b}}$ is the strain at break expressed in percentage $[13,21]$.

At the same time, the maximum attainable strength $\sigma_{\mathrm{MAX}}$, is computable from the stress at break, $\sigma_{\mathrm{b}}$ multiplied by the mechanical draw ratio, following Equation (5):

$\sigma_{\mathrm{MAX}}=\sigma_{\mathrm{b}} \cdot \lambda_{\mathrm{MEC}}=\sigma_{\mathrm{b}}\left(1+\frac{\varepsilon_{\mathrm{b}}}{100}\right)$

These data are compared in Table 5. Mechanical draw ratio of nanocomposite fiber ranged in between 15-20, and correspondingly the calculated maximum strength was between 670 and $1100 \mathrm{MPa}$, with respect to the values of 13 and about $550 \mathrm{MPa}$ of HDPE fiber, respectively. The highest mechanical draw ratio and the maximum strength were obtained for composition at $0.5 \%$ of $\mathrm{LDH}$.

The linear density [48] of spun monofilament slightly increased with the LDH content, from 187 tex of neat HDPE fiber up to 193 tex of LDH-3 fiber. At the same time, the tenacity of nanocomposite fibers containing $0.5-2 \%$ of $\mathrm{LDH}$ was found in the range of 5.4-5.9 cN/tex, much higher than neat HDPE fiber $(4.4 \mathrm{cN} /$ tex $)$, indicating the positive effect of LDH dispersion. On the other hand, at higher LDH content, both the stress at break and tenacity decreased as a possible consequence of a nonhomogenous nanofiller dispersion.

Selected compositions of as-spun filament were drawn ten times at $100^{\circ} \mathrm{C}$, producing fibers of about 158 micron (titer of 19 tex) at higher stiffness and strength. Representative stress-strain curves are shown in Figure 8, whereas tensile results are reported in Table 6. It is well evident that elastic modulus of drawn HDPE-LDH fibers (5.5-5.8 GPa) is higher of about $10-15 \%$ in comparison to neat 
Table 6. Effect of drawing on tensile mechanical properties of neat HDPE and nanofilled HDPE fibers drawn at $100^{\circ} \mathrm{C}$ with $\mathrm{DR}=10$ (diameter 158 micron)

\begin{tabular}{|l|c|c|c|c|c|c|}
\hline Composition & $\begin{array}{c}\text { Tensile modulus } \\
{[\mathbf{G P a}]}\end{array}$ & $\begin{array}{c}\text { Stress at break } \\
{[\mathbf{M P a}]}\end{array}$ & $\begin{array}{c}\text { Strain at break } \\
{[\%]}\end{array}$ & $\begin{array}{c}\text { Mechanical } \\
\text { draw ratio }\end{array}$ & $\begin{array}{c}\text { Calculated } \\
\text { maximum strength } \\
{[\mathbf{M P a}]}\end{array}$ & $\begin{array}{c}\text { Relative } \\
\text { stiffening } \\
\text { factor* }\end{array}$ \\
\hline HDPE & $5.04 \pm 0.50$ & $592 \pm 50$ & $68 \pm 10$ & 1.68 & 994 & 9.2 \\
\hline LDH-1 & $5.54 \pm 0.32$ & $460 \pm 35$ & $98 \pm 5$ & 1.98 & 910 & 9.2 \\
\hline LDH-2 & $5.81 \pm 0.42$ & $470 \pm 40$ & $98 \pm 10$ & 1.98 & 930 & 9.4 \\
\hline LDH-3 & $5.59 \pm 0.10$ & $510 \pm 20$ & $76 \pm 8$ & 1.76 & 897 & 8.5 \\
\hline
\end{tabular}

*relative tensile modulus of draw fiber and as-span fiber

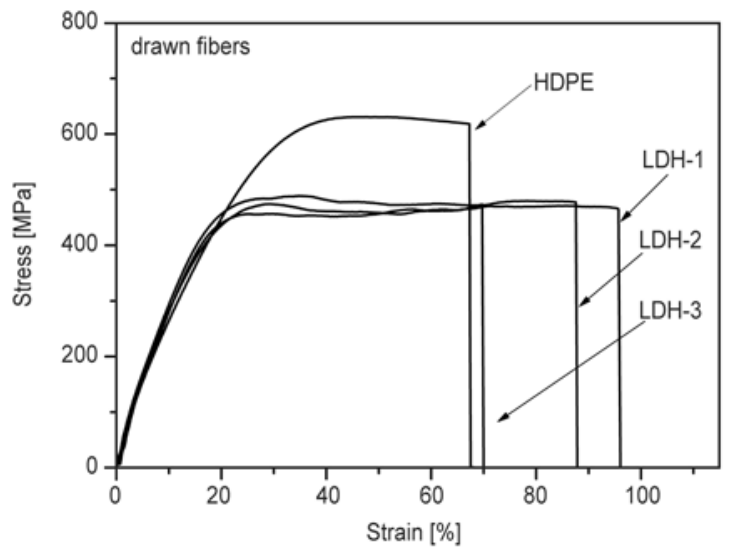

Figure 8. Stress-strain curves of selected fibers of neat HDPE and HDPE nanocomposites drawn ten times at $100^{\circ} \mathrm{C}$

HDPE drawn fibers $(5.0 \mathrm{GPa})$, maintaining the stiffening effect of LDH.

The highest improvement was observed for the composition with $2 \mathrm{wt} \%$ of nanofiller. Together with improvement in modulus, a slightly lower stress at break was observed, whereas strain at break exhibit higher values in comparison to neat HDPE drawn fiber (Figure 8 and Table 6).

In general, the enhancement of mechanical stiffening observed for nanocomposites can be explained as an effect of the alignment of nanofiller particles along the strain direction [18]. This process is very similar to the exfoliation process induced by the flow in polymer/clay nanocomposites with a good affinity between the two components. The elongation flow could be responsible to the break and orientation of the dispersed nanoparticles aggregates even if the viscosity ratio of the two components is very different and this can be the reason of the observed improvement of tensile modulus [49]. On the other hand after addition of LDH and drawing, nanocomposite polyethylene fibers exhibited a slight lower strength $(0.46-0.51 \mathrm{GPa})$ with respect to neat HDPE drawn fibers $(0.59 \mathrm{GPa})$. At the same time deformation at break of drawn LDH-fiber is higher than that of HDPE (68\%). However, the higher the LDH content the lower the deformation at break that decreases from about $100 \%$ for LDH-1 and LDH-2 to $75 \%$ for LDH-3.

The calculated maximum strength of LDH drawn fibers is about $910 \mathrm{MPa}$, with respect to $990 \mathrm{MPa}$ of HDPE drawn fibers. Moreover it is worth noting that the relative stiffening factor, calculated as the ratio between tensile modulus of drawn and as-spun fiber, increase from 9.2 for HDPE and LDH-1, to 9.4 for LDH-2 and decreases to 8.5 for LDH-3 (see Table 6).

It can be concluded that a reinforcement effect for HDPE fibers can be obtained with a relatively small amount of hydrotalcite (in the range of 0.5 and $2 \%$ by wt.) resulting in a positive combination of improved stiffness (elastic modulus), tenacity (stress at break) and strain at break.

\section{Conclusions}

HDPE composites with organically modified hydrotalcite were prepared following two different compounding routes, i.e. internal mixing and compression molding, or twin-screw extrusion and spinning. The effect of filler on the thermo-mechanical properties of high density polyethylene was investigated on compression molded plates and as-spun fibers. In both cases, the dispersion of nanoparticles in a content of $0.5-5 \%$ significantly improved the thermal stability and the elastic modulus of HDPE. The stiffening effect of nanofiller was also confirmed by the proportional increase of Shore D hardness values.

Depending on the lower cooling rate after compression molding, HDPE plates showed a higher crystallinity with respect to the fibers. However, nanocomposites fibers showed a higher improvement of the relative elastic modulus with respect to the nanocomposites plates containing the same percentage of nanofiller. This behaviour could be a consequence of the different orientation and morphology related to the crystallinity developed in the spin- 
ning. These results confirmed that polyethylene containing organically modified hydrotalcite could be easily spinned into nanofilled fibers. The compositions between 0.5 and $2 \%$ by wt. of hydrotalcite resulted the more promising for improving the fiber properties. HDPE-LDH drawn fiber exhibited higher stiffness than correspondent HDPE drawn fiber.

\section{Acknowledgements}

The authors thanks to LyondellBasell Industries - Basell Poliolefine Italia S.r.l. 'Giulio Natta' R\&D and dr. F. Fava (Clariant Masterbatches S.p.A., Pogliano Milanese, MI, Italy) for the formulation and the provision of HDPE hydrotalcite masterbatch. Moreover, prof R. Ceccato (University of Trento) is warmly acknowledged for XRD analysis and for the helpful discussion.

\section{References}

[1] Lefebvre J. M.: Nanocomposites, polymer-clay. in 'Encyclopedia of polymer science and technology' (eds.: Kroschwitz J. I., Mark H. F.) Wiley-Interscience, New York, Vol. 3, 336-352 (2003).

[2] Ke Y. C., Stroeve P.: Polymer-layered silicate and silica nanocomposites. Elsevier, Amsterdam (2005).

[3] Ray S. S., Okamoto M.: Polymer/layered silicate nanocomposite: A review from preparation to processing. Progress in Polymer Science, 28, 1539-1641 (2003). DOI: $10.1016 /$ j.progpolymsci.2003.08.002

[4] Giannellis E. P.: Polymer-layered silicate nanocomposites: Synthesis, properties and applications. Applied Organometallic Chemistry, 12, 675-680 (1998). DOI: 10.1002/(SICI)1099-0739(199810/11)12:10/11< 675::AID-AOC779>3.0.CO;2-V

[5] Paul D. R., Robeson L. M.: Polymer nanotechnology: Nanocomposites. Polymer, 49, 3187-3204 (2008). DOI: $10.1016 /$ j.polymer.2008.04.017

[6] Costa F. R., Abdel-Goad M., Wagenknecht U., Heinrich G.: Nanocomposites based on polyethylene and $\mathrm{Mg}-\mathrm{Al}$ layered double hydroxide. I. Synthesis and characterization. Polymer, 46, 4447-4453 (2005).

DOI: $10.1016 /$ j.polymer.2005.02.027

[7] Costa F. R., Wagenknecht U., Heinrich G.: LDPE/MgAl layered double hydroxide nanocomposite: Thermal and flammability properties. Polymer Degradation and Stability, 92, 1813-1823 (2007).

DOI: $10.1016 /$ j.polymdegradstab.2007.07.009

[8] Ciardelli F., Coiai S., Passaglia E., Pucci A., Ruggeri G.: Nanocomposites based on polyolefins and functional thermoplastic materials. Polymer International, 57, 805-836 (2008).

DOI: $10.1002 /$ pi.2415

[9] Tonnaer H.: New synthetic organoclays offer improved flame retardancy and gas barrier properties. Plastics, Additives and Compounding, 11, 14-17 (2009). DOI: $\underline{10.1016 / \text { S1464-391X(09)70077-7 }}$
[10] Marega C., Causin V., Marigo A., Ferrara G., Tonnaer H.: Perkalite as an innovative filler for isotactic polypropylene-based nanocomposites. Journal of Nanoscience and Nanotechnology, 9, 2704-2714 (2009). DOI: 10.1166/jnn.2009.dk01

[11] Marega C., Causin V., Neppalli R., Saini R., Ferrara G., Marigo A.: The effect of a synthetic double layer hydroxide on the rate of II $\rightarrow$ I phase transformation of poly(1-butene). Express Polymer Letters, 12, 10501061 (2011).

DOI: 10.3144/expresspolymlett.2011.103

[12] Dorigato A., D’Amato M., Pegoretti A.: Thermomechanical properties of high density polyethylene fumed silica nanocomposites: Effect of filler surface area and treatment. Journal of Polymer Research, 19, 9889-9899 (2012).

DOI: $10.1007 / \mathrm{s} 10965-012-9889-2$

[13] George Tomka J.: Textile fiber. in 'Comprehensive polymer science’ (eds.: Booth C., Price C.) Pergamon Press, Oxford, Vol. 2, 487-510 (1989).

[14] La Mantia F. P., Tzankova Dintcheva N., Scaffaro R., Marino R.: Morphology and properties of polyethylene/clay nanocomposites drawn fibers. Macromolecular Materials and Engineering, 293, 83-91 (2008).

DOI: $10.1002 /$ mame.200700204

[15] La Mantia F. P., Marino R., Tzankova Dintcheva N.: Morphology modification of polyethylene/clay nanocomposite samples under convergent flow. Macromolecular Materials and Engineering, 294, 575-581 (2009). DOI: $10.1002 /$ mame.200900066

[16] Chantrasakul S., Amornsakchai T.: High strength polyethylene fibers from high density polyethylene/organoclay composites. Polymer Engineering and Science, 47, 943-950 (2007). DOI: $10.1002 /$ pen.20778

[17] Rattanawijan W., Amornsakchai T.: Polyethylene composite fibers. I: Composite fibers of high-density polyethylene. Journal of Applied Polymer Science, 124, 501-509 (2012). DOI: $10.1002 /$ app.34863

[18] D’Amato M., Dorigato A., Fambri L., Pegoretti A.: High performance polyethylene nanocomposite fibers. Express Polymer Letters, 6, 954-964 (2012). DOI: $10.3144 /$ expresspolymlett.2012.101

[19] Pavliková S., Thomann R., Reichert P., Mülhaupt R., Marcincin A., Borsig E.: Fiber spinning from poly (propylene)-organoclay nanocomposite. Journal of Applied Polymer Science, 89, 604-611 (2003). DOI: $10.1002 /$ app. 11870

[20] Joshi M., Shaw M., Butola B. S.: Studies on composite filaments from nanoclay reinforced polypropylene. Fibers and Polymers, 5, 59-67 (2004). DOI: $10.1007 / \mathrm{BF} 02875496$

[21] Lorenzi D., Sartori G., Ferrara G., Fambri L.: Spinnability of nanofilled polypropylene. Macromolecular Symposia, 301, 73-81 (2011). DOI: $10.1002 /$ masy.201150310 
[22] Rangasamy L., Shim E., Pourdeyhimi B.: Structure and tensile properties of nanoclay-polypropylene fibers produced by melt spinning. Journal of Applied Polymer Science, 121, 410-419 (2011).

DOI: $10.1002 /$ app.33619

[23] Bhat G., Hedge R. R., Kamath M. G., Deshpande B.: Nanoclay reinforced fibers and nonwovens. Journal of Engineered Fibers and Fabrics, 3, 22-34 (2008).

[24] Guo Z., Hagström B.: Preparation of polypropylene/ nanoclay composite fibers. Polymer Engineering and Science, in press (2013). DOI: $10.1002 /$ pen.23463

[25] Van Krevelen D. W.: Properties of polymers. Elsevier, Amsterdam (1990).

[26] Costa F. R., Satapathy B. K., Wagenknecht U., Weidisch R., Heinrich G.: Morphology and fracture behaviour of polyethylene/Mg-Al layered double hydroxide (LDH) nanocomposites. European Polymer Journal, 42, 2140-2152 (2006).

DOI: 10.1016/j.eurpolymj.2006.04.005

[27] Ramírez-Vargas E., Sánchez-Valdes S., Parra-Tabla O., Castañeda-Gutiérrez S., Méndez-Nonell J., RamosdeValle L. F., López-León A., Lujan-Acosta R.: Structural characterization of LDPE/EVA blends containing nanoclay-flame retardant combinations. Journal of Applied Polymer Science, 123, 1125-1136 (2012). DOI: 10.1002/app.34586

[28] Wang Q., Zhang X., Wang C. J., Zhu J., Guo Z., O'Hare D.: Polypropylene/layered double hydroxide nanocomposites. Journal of Materials Chemistry, 22, 19113-19121 (2012).

DOI: $10.1039 / \mathrm{C} 2 \mathrm{JM} 33493 \mathrm{C}$

[29] Costa F. R., Leuteritz A., Meinl J., Wagenknecht U., Heinrich G.: LDH as nanofiller: Organic modification and dispersion in polymers. Macromolecular Symposia, 301, 46-54 (2011).

DOI: $10.1002 /$ masy.201150307

[30] Ye L, Wu Q.: Effects of an intercalation agent on the morphology and thermal and flame-retardant properties of low-density polyethylene/layered double hydroxide nanocomposites prepared by melt intercalation. Journal of Applied Polymer Science, 123, 316-323 (2012).

DOI: $10.1002 /$ app. 33770

[31] Kontou E., Niaounakis M.: Thermo-mechanical properties of LLDPE/SiO $/ \mathrm{S}_{2}$ nanocomposites. Polymer, 47, 1267-1280 (2006).

DOI: $10.1016 /$ j.polymer.2005.12.039

[32] McCrum N. G., Read B. E., Williams G.: Anelastic and dielectric effects in polymeric solids. Wiley, New York (1967).

[33] Passaglia E., Coiai S., Giordani G., Taburoni E., Fambri L., Pagani V., Penco M.: Modulated crosslinking of polyolefins through radical processes in the melt. Macromolecular Materials and Engineering, 289, 809-817 (2004).

DOI: $\underline{10.1002 / \mathrm{mame} .200400155}$
[34] Hippi U., Mattila J., Korhonen M., Seppälä J.: Compatibilization of polyethylene/aluminum hydroxide (PE/ATH) and polyethylene/magnesium hydroxide (PE/MH) composites with functionalized polyethylenes. Polymer, 44, 1193-1201 (2003).

DOI: 10.1016/S0032-3861(02)00856-X

[35] Kolařík J., Kruliš Z., Šlouf M., Fambri L.: High-density polyethylene/cycloolefin copolymer blends. Part 1: Phase structure, dynamic mechanical, tensile, and impact properties. Polymer Engineering and Science, 45, 817-826 (2005). DOI: $10.1002 /$ pen.20337

[36] Tian Y., Zhang H., Qin J., Yu J., Cheng L., Lv Q.: Effect of the ethylene-acrylic acid melt index on the structural characteristics and properties of high-density polyethylene/layered double hydroxide nanocomposites prepared via the master-batch method. Journal of Composite Materials, in press (2013).

DOI: $10.1177 / 0021998312470153$

[37] Gilman J. W.: Flammability and thermal stability studies of polymer layered-silicate (clay) nanocomposites. Applied Clay Science, 15, 31-49 (1999).

DOI: 10.1016/S0169-1317(99)00019-8

[38] Chen W., Qu B.: LLDPE/ZnAl LDH-exfoliated nanocomposites: Effects of nanolayers on thermal and mechanical properties. Journal of Materials Chemistry, 14, 1705-1710 (2004).

DOI: $10.1039 / \mathrm{B} 401790 \mathrm{~K}$

[39] Ding P., Qu B.: Synthesis of exfoliated PP/LDH nanocomposites via melt-intercalation: Structure, thermal properties, and photo-oxidative behavior in comparison with PP/MMT nanocomposites. Polymer Engineering and Science, 46, 1153-1159 (2006).

DOI: $10.1002 /$ pen.20568

[40] Costantino U., Gallipoli A., Nocchetti M., Camino G., Bellucci F., Frache A.: New nanocomposites constituted of polyethylene and organically modified ZnAlhydrotalcites. Polymer Degradation and Stability, 90, 586-590 (2005).

DOI: 10.1016/j.polymdegradstab.2005.05.019

[41] Amornsakchai T., Songtipya P.: On the influence of molecular weight and crystallization condition on the development of defect in highly drawn polyethylene. Polymer, 43, 4231-4236 (2002). DOI: $10.1016 / \mathrm{S} 0032-3861(02) 00208-2$

[42] Deshmane C., Yuan Q., Perkins R. S., Misra R. D. K.: On striking variation in impact toughness of polyethylene-clay and polypropylene-clay nanocomposite systems: The effect of clay-polymer interaction. Materials Science and Engineering A, 458, 150-157 (2007). DOI: $10.1016 /$ j.msea.2006.12.069

[43] Xu J-T., Wang Q., Fan Z-Q.: Non-isothermal crystallization kinetics of exfoliated and intercalated polyethylene/montmorillonite nanocomposites prepared by in situ polymerization. European Polymer Journal, 41, 3011-3017 (2005). DOI: $10.1016 /$ j.eurpolymj.2005.04.042 
[44] Ahmed S., Jones F. R.: A review of particulate reinforcement theories for polymer composites. Journal of Materials Science, 25, 4933-4942 (1990).

DOI: $10.1007 / \mathrm{BF} 00580110$

[45] Pegoretti A., Dorigato A., Penati A.: Tensile mechanical response of polyethylene-clay nanocomposites. Express Polymer Letters, 1, 123-131 (2007).

DOI: $10.3144 /$ expresspolymlett.2007.21

[46] He D., Jiang B.: The elastic modulus of filled polymer composites. Journal of Applied Polymer Science, 49, 617-621 (1993).

DOI: $\underline{10.1002 / a p p .1993 .070490408}$
[47] Mareri P., Bastide S., Binda N., Crespy A.: Mechanical behaviour of polypropylene composites containing fine mineral filler: Effect of filler surface treatment. Composites Science and Technology, 58, 747-752 (1998).

DOI: $10.1016 / \mathrm{S} 0266-3538(97) 00156-5$

[48] ASTM D123-13a: Standard terminology relating to textile (2013).

DOI: $10.1520 / \mathrm{D} 0123$

[49] Tokihisa M., Yakemoto K., Sakai T., Utracki L. A., Sepehr M., Li J., Simard Y.: Extensional flow mixer for polymer nanocomposites. Polymer Engineering and Science, 46, 1040-1050 (2006).

DOI: $10.1002 /$ pen.20542 